\title{
Proposta de framework conceitual para a integração do ensino de softwares para representação com conhecimentos em design
}

Proposal of conceptual framework for the integration of representation software teaching with design knowledges.

MAZZAROTTO FILHO, Marco André; Mestre e doutorando.; UFPR

marcomazzarotto@gmail.com

ULBRICHT, Vânia Ribas; Doutora; UFSC

vrulbricht@gmail.com

\section{Resumo}

Este artigo apresenta uma proposta de framework conceitual para a integração do ensino de softwares para representação com o ensino de outros conhecimentos de design. Sua proposição busca auxiliar na resolução de dois problemas durante o ensino em cursos superiores de design: (a) a pouco importância data aos conhecimentos de tipo estratégico durante o ensino de softwares e (b) a falta de contextualização do ensino de softwares como ferramentas que servem a determinados propósitos durante o processo de design. Como metodologia, utiliza de uma pesquisa bibliográfica, sendo que a principal base para o desenvolvimento do framework é a teoria dos tipos de conhecimento, que podem ser divididos em declarativos, procedimentais e estratégicos.

Palavras Chave: representação de design, softwares, ensino de design.

\section{Abstract}

This article presents a conceptual framework proposal for the integration of representation software teaching with other design knowledges. The proposal seeks to assist in solving two problems during teaching in higher education courses: (a) the little relevance to strategic knowledge during software teaching and (b) the lack of contextualization of teaching software as tools that serve particular purposes during the design process. The methodology uses a bibliographic research, and the main basis for the development of the framework is the theory of types of knowledge, which can be divided into declarative, procedural and strategic.

Keywords: design representation, softwares, design teaching. 


\section{Introdução}

A produção de representações visuais é uma atividade central para o processo de design gráfico. Autores como Galle (1999) inclusive defendem que design deve ser definido como o processo de produção de representações de design, sendo a representação da solução o principal produto de um projeto. Se antes do advento das tecnologias digitais a maior parte das representações precisavam ser desenvolvidas manualmente, a partir da inserção do computador no processo elas passam a poder ser produzidas também digitalmente.

A importância em possuir habilidades no uso de softwares para a produção de representações de design pode ser confirmada pela demanda do mercado por profissionais que já possuam esses conhecimentos e também pela presença de disciplinas nessa área na grande maioria dos cursos de design gráfico (MARSHALL \& MEACHEM, 2007).

Porém, como aponta Spitz (1995), a inserção do ensino de softwares em cursos de design ocorreu de forma isolada, sem integrar esse ensino com os outros conhecimentos e habilidades abordados nas demais disciplinas. Para Stout apud Marshall \& Meachem (2007), essa falta de integração é problemática, pois - usando uma metáfora - pode levar a formação de 'macacos de computador', muito bons em usar as tecnologias, mas deixando o 'rabo balançar o cachorro', já que ao não terem um entendimento claro de como organizar textos e elementos para criar uma mensagem eficaz, deixam o computador cuidar disso por eles.

A partir desse problema surge o objetivo principal deste artigo, que é apresentar um framework conceitual capaz de auxiliar no desenvolvimento de novas estratégias de ensino mais integradas. Com base nesse framework, é possível entender melhor quais são os diferentes tipos de conhecimento envolvidos no processo de aprendizagem de softwares para representação de design e como eles podem ser relacionados e integrados.

Como método, este trabalho utilizou apenas da revisão de literatura na área de ensino de softwares para representação. Estruturalmente, excluindo a introdução e conclusão, o artigo está dividido em mais quatro partes: (a) o tópico dois apresenta os diferentes tipos de conhecimento envolvidos na aprendizagem de software; (b) em seguida são apresentados os problemas de falta de integração no ensino; (c) o quarto tópico apresenta a proposta de framework desenvolvido; e (d) o quinto tópico demonstra um exemplo de utilização do framework para integrar os diversos tipos de conhecimento envolvido no ensino de um tema de design.

\section{Tipos de conhecimento}

Entender os diferentes tipos de conhecimento é um passo inicial importante para compreender suas possíveis relações e traçar estratégias para integrá-los durante o processo de ensino, considerando tanto conhecimentos em design quanto em softwares para representação. Essa tipologia também fornece categorias de análise que permitem identificar melhor onde estão os problemas de integração nos modelos atuais de ensino.

Segundo Pinto (1998), os conhecimentos de um estudante podem ser classificados em três categorias:

- Conhecimento declarativo (CD): É constituído por proposições verdadeiras cujo conteúdo total pode ser expresso verbalmente, como teorias, definições, fatos, 
nomes, etc.

- Conhecimento procedimental (CP): Refere-se à habilidade em realizar determinada ação, como desenhar ou utilizar o computador.

- Conhecimento estratégico (CE): É o tipo de conhecimento que permite a escolha de quais CDs e CPs são mais adequados para cada situação. É um conhecimento de natureza estratégica que busca otimizar a realização das atividades.

Podemos entender, portanto, o conhecimento declarativo como aquele que define e explica o que as coisas são, o procedimental apresenta como utilizá-las e aplicá-las, enquanto o estratégico busca avaliar e selecionar qual ou quais são as melhores opções a serem utilizadas e em quais momentos. Aplicado ao contexto da aprendizagem de softwares, o conhecimento declarativo pode ser entendido como o reconhecimento de uma ferramenta, seu nome, elementos que a compõem e funções. Já o conhecimento procedimental consiste na habilidade em utilizar essa ferramenta, o passo a passo de ações necessário para a sua completa aplicação. Por fim, o conhecimento estratégico representa a habilidade em selecionar quais ferramentas e quais sequências de passos são mais adequadas para resolução de um determinado problema em um determinado contexto.

De forma complementar, Chester (2007) explica esses três tipos de conhecimento aplicado ao ensino de software da seguinte maneira:

- CD em software: Envolve conhecer os comandos e ferramentas disponíveis, assim como quais tarefas podem ser realizadas com determinado software. 0 conhecimento sobre esses aspectos do software é necessário antes que ele possa ser utilizado.

- CP em software: É o conhecimento que possibilita ao estudante utilizar as ferramentas para executar tarefas no software.

- CE em software: Incluiu uma série de processos metacognitivos, como o planejamento, seleção, monitoramento e revisão das estratégias de uso do software.

A partir destas categorias, o tópico a seguir discutirá os problemas atuais na integração dos conhecimentos durante o ensino de design em cursos superiores.

\section{Problemas na integração dos conhecimentos}

Analisando o ensino atual de softwares para representação em cursos de design é possível notar a ocorrência de dois problemas relacionados à falta de integração entre os conhecimentos:

1. A falta de integração entre os tipos de conhecimento declarativo, procedimental estratégico.

2. A falta de integração entre os conhecimentos em software e os respectivos conhecimentos de design ao qual ele devem suprir como ferramenta.

Ambas os problemas serão discutidos a seguir. 


\subsection{A falta de integração do conhecimento estratégico em software com os demais}

Começando pelo primeiro problema, autores como Arnold (2010) e Chester (2007) apontam para a falha generalizada do ensino de softwares para representação em abordar adequadamente conhecimentos estratégicos, focando apenas no ensino de conhecimentos declarativos e procedimentais. Para Chester, esse tipo de conhecimento dificilmente é apresentado na documentação dos softwares, em tutorias para o seu uso ou até mesmo em aulas sobre o tema. Para Arnold, é comum o ensino de representação digital abordar apenas a operação do software, sem desenvolver os conhecimentos estratégicos necessários para a tomada de decisões referente às formas mais apropriadas de aplica-lo durante o processo de design.

Para Chester (2007), alcançar um alto nível de perícia no uso de softwares gráficos tem relação direta com o conhecimento estratégico, pois apenas através dele é possível escolher quais métodos e ferramentas devem ser utilizados, monitorar o progresso, prever consequências, avaliar procedimentos e alterar o caminho quando for necessário. Ou seja, apenas através do conhecimento estratégico é possível que o estudante alcance autonomia no uso do software, podendo transferir o conhecimento para novos cenários de aplicação e para resolução de novos problemas, e não apenas repetindo passo a passo procedimentos decorados.

Com base nisso, Chester (2007) aponta que o ensino atual de softwares deve ser transformado de modo a integrar também o conhecimento estratégico, além do declarativo e do procedimental. Para o autor não só é possível como também é fortemente recomendado inserir intervenções que permitam aprender esse tipo de conhecimento. Essas intervenções podem ser de quatro tipo: a) deixar claro aos estudantes que existem diferentes estratégias a serem tomadas dependendo do contexto e do objetivo; b) prover instruções sobre quando utilizar cada estratégia; c) prover instruções sobre como utilizar cada estratégia; e d) prover instrução e oportunidades para transferir o conhecimento para outras situações.

\subsection{A falta de integração entre conhecimentos em software e em design}

Marshall \& Meachem (2007) apontam que a inserção do ensino de softwares em cursos de design no final da década de 90 foi mais reativa do que proativa. Para as autoras, as instituições inseriram esses conteúdos apenas como resposta às pressões do mercado e dos alunos, e não devido a um entendimento de como a sua inserção poderia melhorar a formação de um designer e ser integrado aos demais conhecimentos. Como resultado, o ensino foi estruturado através de disciplinas isoladas e completamente separado da prática projetual. No contexto brasileiro, Spitz (1995) aponta que foi comum encontrar o ensino de softwares para representação totalmente desvinculado das demais disciplinas, alocadas em laboratórios especiais, dentro ou fora dos departamentos, mas invariavelmente isolados da poeira, argila, vernizes e tintas e de outros materiais que fazem parte do cotidiano do design.

Zhang et al (2008), Kuang (2008) e Zhu \& Zhang (2010), criticam a ênfase excessiva na aprendizagem das ferramentas de cada software sem a devida conexão com o seu uso para os processos criativos de design. Zhang et al defendem a importância de apresentar o computador como apenas mais uma ferramenta, sem valor em si só, mas apenas quando auxilia adequadamente na expressão do pensamento. Para os autores, o ensino em cursos de design muitas vezes foca apenas na aprendizagem de diferentes softwares e seus comandos, mas 
ignoram como combiná-los com a prática do design. Como resultado, é possível encontrar alunos com grande competência na operação dos programas, mas com deficiências em habilidades básicas de design e pensamento criativo. Para Kuang, muitos cursos de design ainda utilizam métodos tradicionais para ensinar representação digital, métodos estes que seriam baseados no professor demonstrando passo a passo como efetuar uma tarefa, para em seguida os alunos repetirem as operações. Esse ensino abordaria detalhadamente todos os menus e ferramentas do software, de modo que os estudantes aprendem o operar o software completamente. Porém, a ausência da integração com a prática do design gera dificuldades para esses alunos aplicarem com autonomia esses conhecimentos para a produção de projetos de design. Zhu \& Zhang também apontam que o ensino baseado em professores demonstrando e alunos imitando é uma prática comum. Para os autores, essa prática leva a estudantes que sabem reproduzir bem modelos digitais dados, mas que tem dificuldades em criar modelos novos a partir de conceitos de design propostos por eles mesmos.

Portanto, de forma geral, percebemos uma forte tendência em o ensino de software para representação em design focar de forma isolada e descontextualizada apenas na ferramenta, com pouca ou nenhuma relação com os respectivos conhecimentos em design para qual essa ferramenta se presta. Como forma de auxiliar na superação dessa falha no ensino, o tópico a seguir pretende apresentar uma proposta de framework que auxilia a estruturação de estratégias pedagógicas integradas de ensino nessa área.

\section{Framework para integração dos conhecimentos}

São duas as implicações da adoção da teoria dos tipos de conhecimento para a construção do modelo de ensino integrado. A primeira é referente à própria integração e completude dos conhecimentos em software, que deve abordar os três tipos de conhecimentos: declarativo, procedimental e estratégico, este último muitas vezes negligenciado durante o ensino de softwares para representação de design. Já a segunda implicação é a possibilidade de utilizar a teoria como framework capaz de apresentar caminhos para a integração dos conhecimentos em software e em design. Ambas as implicações são abordadas a seguir.

A figura 1 apresenta a oposição entre dois tipos de ensino de softwares para representação analisados a partir do framework dos tipos de conhecimento. A imagem da esquerda representa o modelo de ensino de softwares para representação gráfica que - segundo Arnold (2010) e Chester (2007) - é o mais comum. Como pode ser observado, esse modelo é incompleto, pois foca apenas nos conhecimentos declarativos (o que é) e procedimentais (como usar), apresentando lacunas na abordagem de conhecimentos estratégicos (qual e quando utilizar). Já a imagem da direita, apresenta um modelo completo de ensino de softwares para representação digital, já que aborda os três tipos de conhecimento de forma integrada. 
Figura 1 - Conhecimentos completo e incompleto em software.

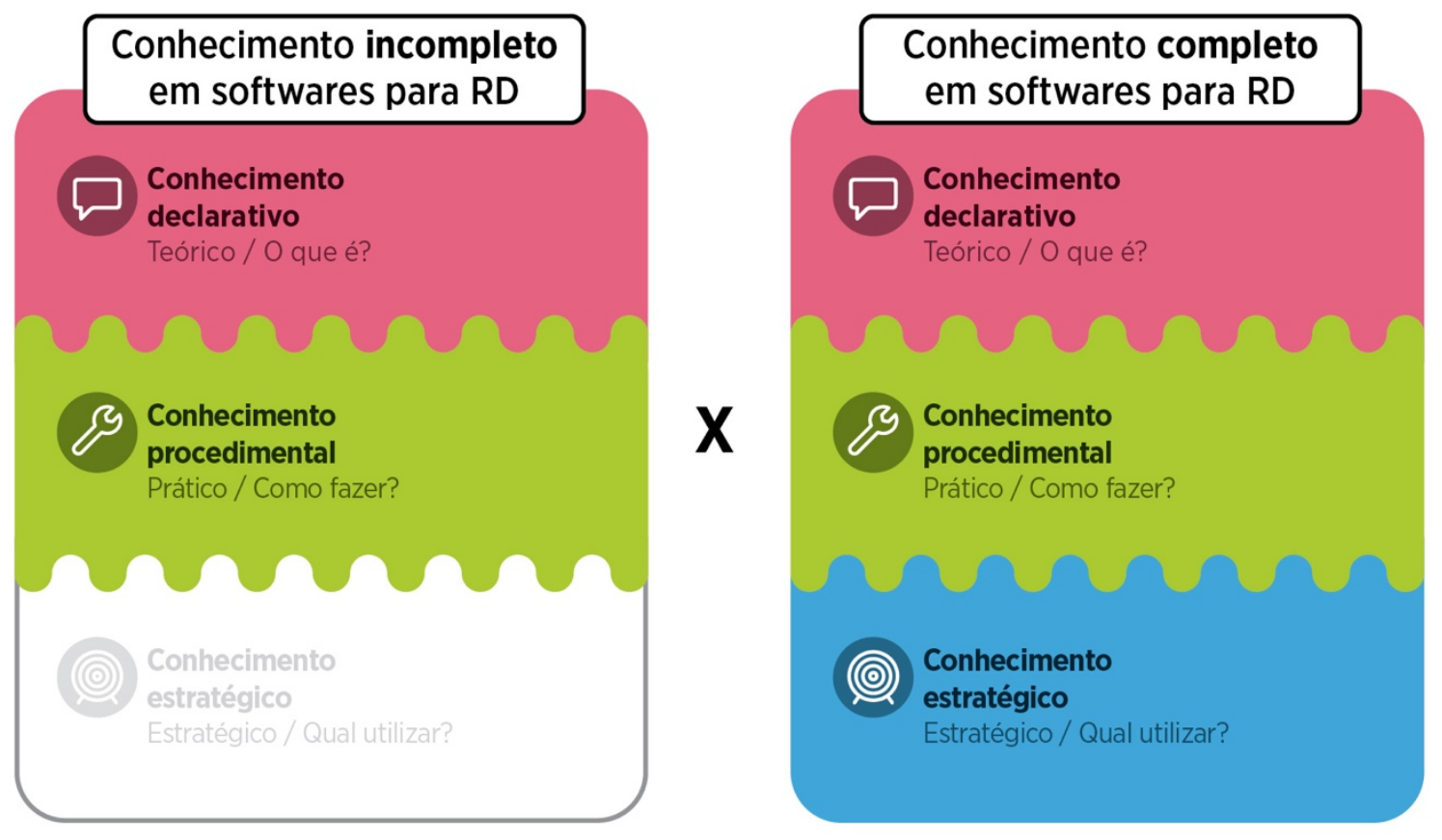

Fonte: 0 autor.

Essa mesma tipologia de conhecimentos pode ser aplicada para o design, que também apresenta conhecimentos declarativos, procedimentais e estratégicos. Porém, como já apontado anteriormente, o modelo padrão em cursos superiores é baseado no ensino de design separado do ensino de softwares para representação, conforme apresentado na figura 2. Como pode ser observado, dessa maneira são construídas poucas relações entre os conhecimentos declarativos, procedimentais e estratégicos de cada um, que acabam sendo ensinados de forma fragmentada e pouco conectada. 
Figura 2 - Falta de integração entre os conhecimentos declarativos, procedimentais e estratégico de design com os de software.
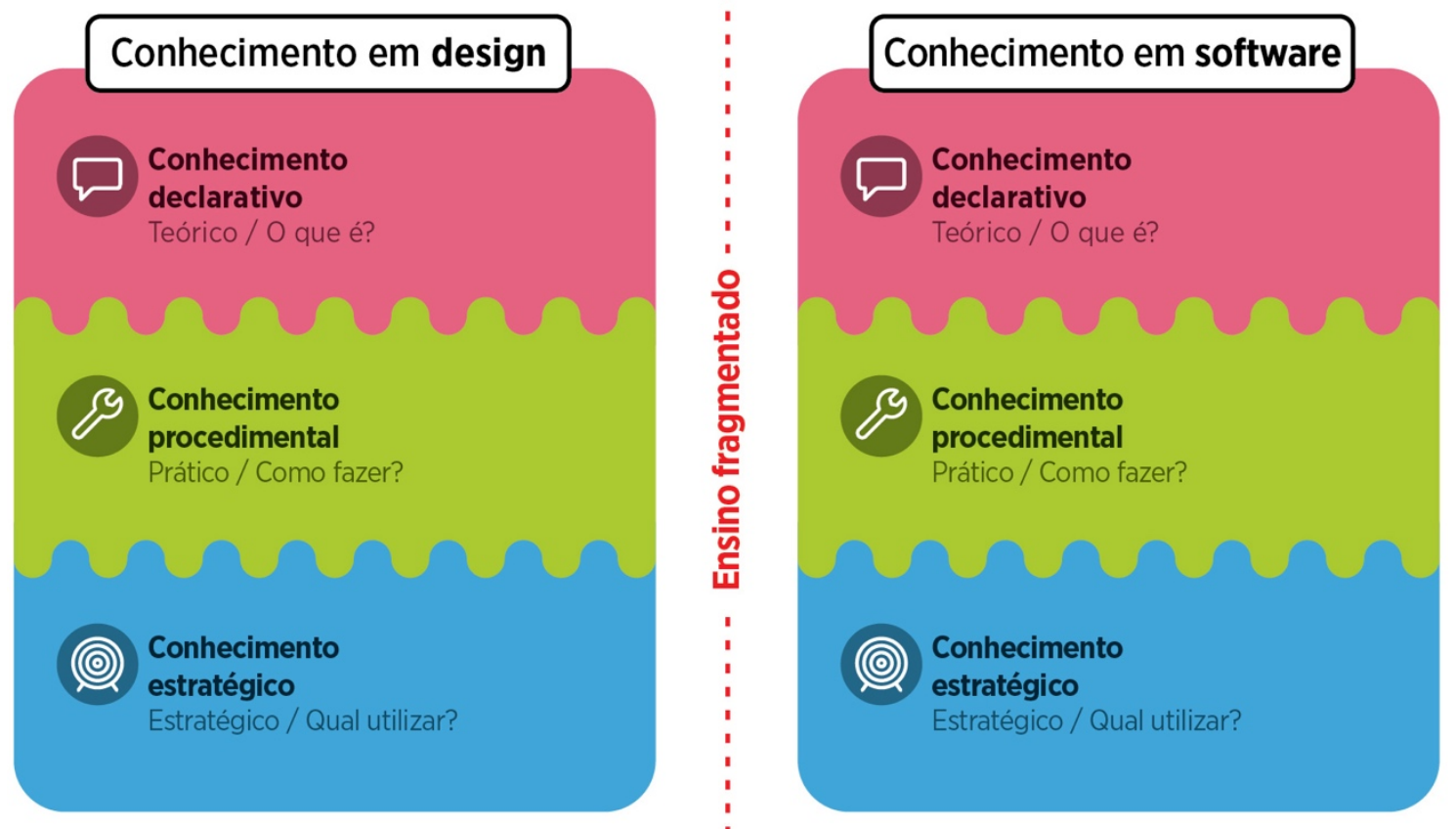

Fonte: o autor.

Como já apontado, essa fragmentação no ensino pode acarretar em problemas na formação de designers, que podem ter domínio da ferramenta software, mas pouca habilidade e independência em aplicá-la dentro do processo de design. Além disso, a falta de relação entre os conhecimentos não favorece uma aprendizagem significativa, o que diminui a retenção dos conteúdos e a habilidade em transferi-los para novos contextos de uso.

Essa falta de integração no ensino não reflete a realidade da prática do design, pois, como já foi discutido, a representação tem função central para a prática projetual, servindo como ferramenta tanto de exploração quanto de comunicação das ideias. Nesse sentido, como ferramenta prática, o conjunto de habilidades em representação podem ser considerados como conhecimentos procedimentais de design. Dessa maneira, podemos integrar o conjunto de conhecimentos declarativos, procedimentais e estratégicos de software, que tem como objetivo uma função prática e ferramental para o design, encapsulados como um conhecimento procedimental deste, também ligados, portanto, aos seus conhecimentos declarativos e estratégicos. 
Figura 3 - Framework conceitual para a integração entre conhecimentos em softwares e em design.

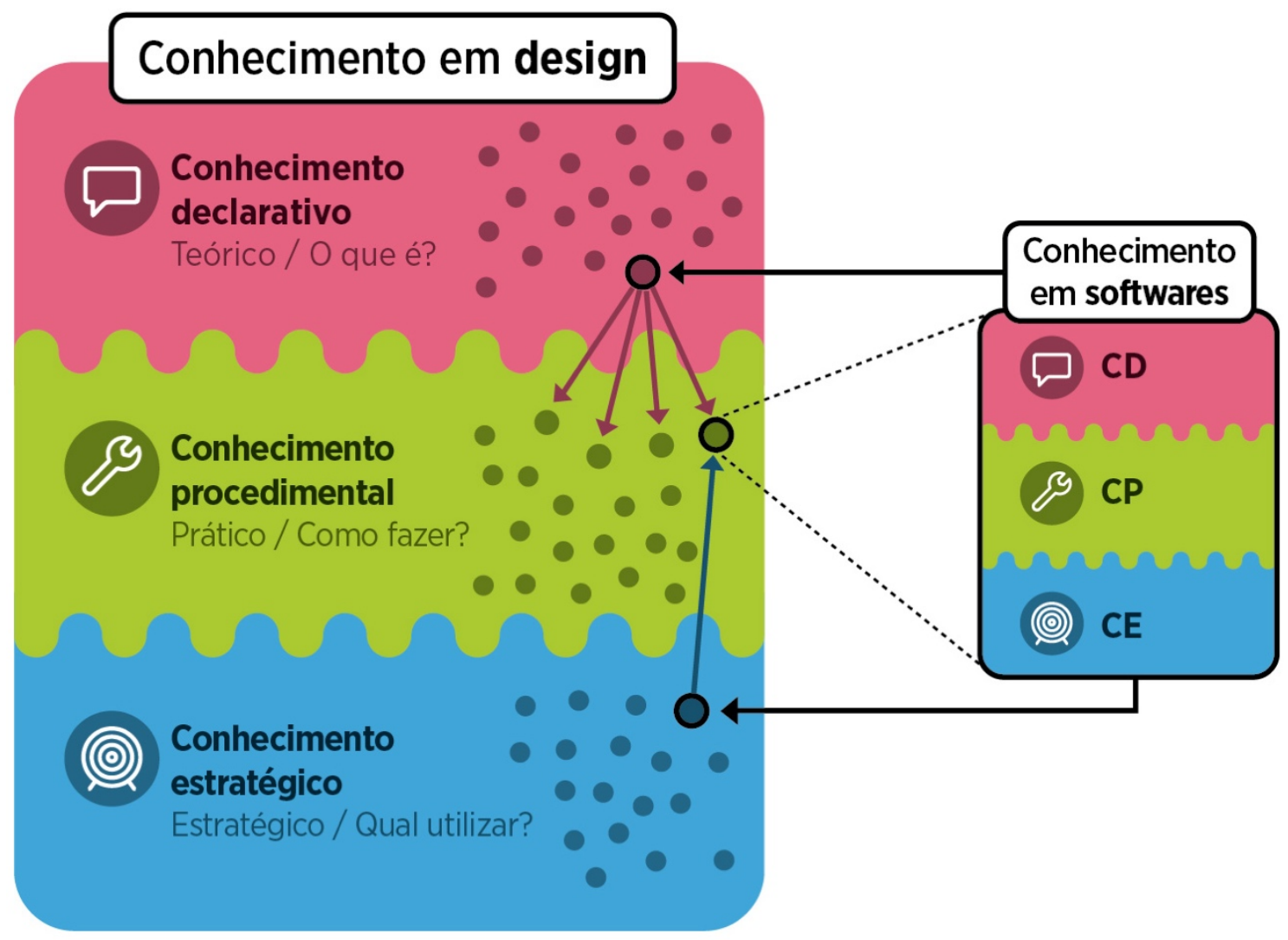

Fonte: o autor.

Essa relação forma um framework conceitual que viabiliza a integração entre os dois grupos de conhecimentos, conforme representando na figura 3. Como pode ser observado, o conhecimento total em design de um estudante é formado por inúmeros conhecimentos específicos, representados na forma de pequenos círculos na figura. Esses conhecimentos podem ser classificados em declarativos (o que é), procedimentais (como fazer) e estratégicos (quais utilizar). Essa categorização é valida tanto para conhecimentos em design (conjunto maior na esquerda) quanto em software (conjunto menor da direita). Os conhecimentos declarativos em design representam aspectos teóricos, conceitos, definições e descrições que, para serem implementadas, necessitam das habilidades práticas e instrumentais dos conhecimentos procedimentais. Como os círculos ligados por setas na figura mostram, um conhecimento declarativo pode ser implementado através de diferentes estratégias práticas, qual é a mais eficiente e apropriada para cada caso, é uma escolha que depende dos conhecimentos estratégicos. É nesse plano geral de conhecimentos em design que podemos integrar os conhecimentos em software. Como habilidades instrumentais que objetivam a construção de representações, o conjunto de conhecimentos específicos em softwares (CD, CP e CE) podem ser considerados como um conhecimento procedimental dentro do conjunto maior de conhecimento em design. Dessa forma, o ensino de software pode ser conectado ao ensino de design, sendo considerado um conhecimento procedimental deste, ligado, por consequência também aos conhecimentos declarativos deste e influenciando no processo de tomadas de decisão no nível 
estratégico.

Concluindo, é possível perceber a importância da teoria dos tipos de conhecimento para um futuro modelo de ensino integrado, apresentando um papel dublo e dois níveis de integração. O primeiro nível corresponde apenas aos conhecimentos em software, que precisam ser completos, integrando tanto conhecimentos declarativos e procedimentais, quanto estratégicos. O segundo nível, corresponde a integração deste conjunto de conhecimentos com o conhecimento procedimental em design, estando, por consequência, também ligado aos conhecimentos declarativos e estratégicos deste.

\section{Exemplo de aplicação do framework}

Neste tópico é apresentado um exemplo da aplicação do framework proposto anteriormente para integrar conhecimentos específicos em softwares para representação digital com conhecimentos mais amplos em design. O exemplo proposto envolve o elemento básico de design gráfico conhecido como grid, muito utilizado para a composição visual e diagramação de livros, revistas e inúmeros outros produtos comunicacionais. O grid é um apanhado de linhas guias e espaços delimitados que auxilia na organização visual de uma página, acelerando o processo de diagramação, facilitando a tomada de decisões visuais e conferindo consistência e unidade a uma publicação. Como ferramenta de design gráfico, o grid precede a existência dos computadores, mas seu uso foi posteriormente também incorporado por softwares voltados para esta área. A figura 4 apresenta uma imagem de captura da tela do software para editoração eletrônica Adobe InDesign com uma página contendo um grid de três colunas.

Figura 4 - Captura de tela do software Adobe InDesign apresentando uma página com um grid de três colunas.

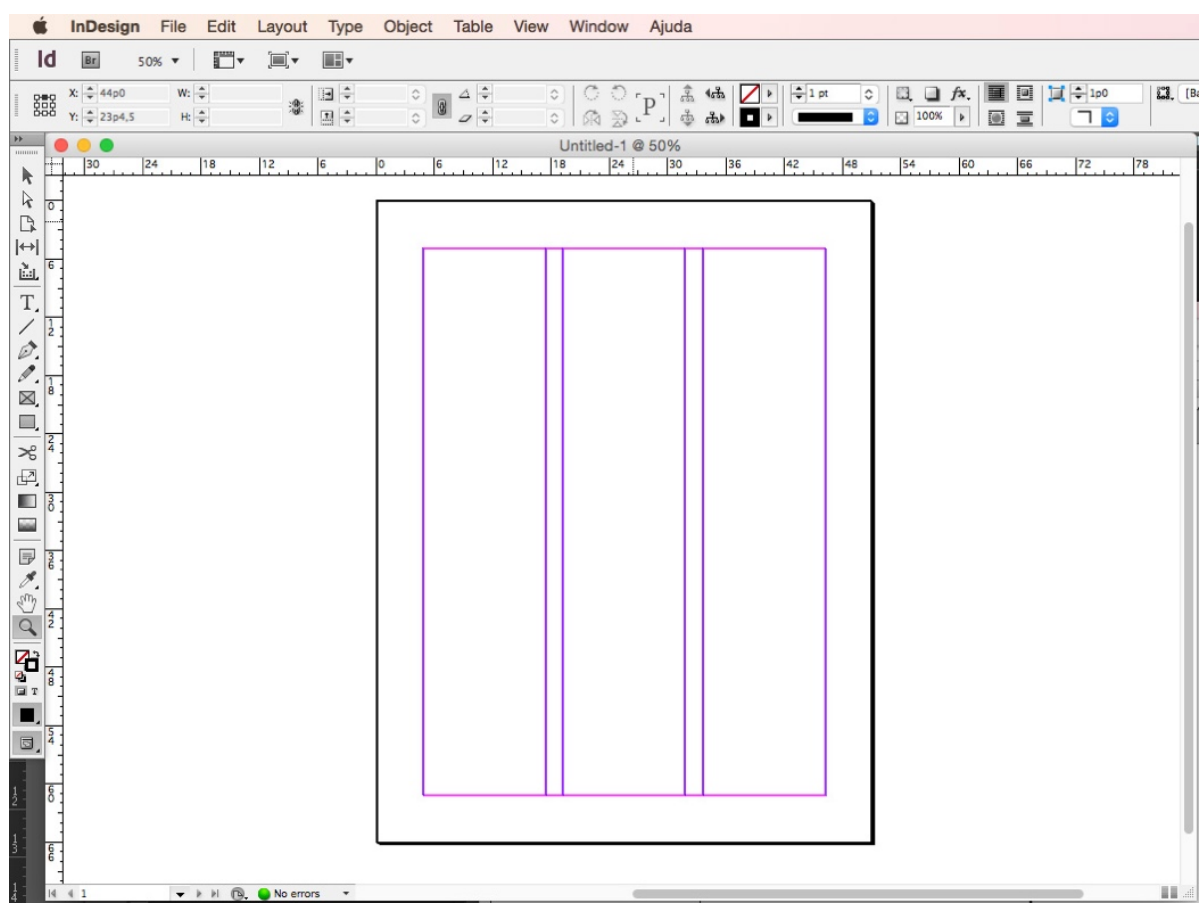


Uma abordagem convencional e limitada para ensinar o uso do grid durante o ensino de representação digital seria apenas abordar os conhecimentos declarativos e procedimentais do software. Ou seja, apresentar as ferramentas que podem ser utilizadas para construir essas linhas guias (conhecimento declarativo) e o passo a passo básico para fazer isso (conhecimento procedimental). Como já apontado, essa abordagem, apesar de ser a mais comum, apresenta deficiências, pois ignora os conhecimentos estratégicos no uso do software, além de não fazer conexões diretas com todos os outros conhecimentos relacionados ao grid no campo do design.

Nesse sentido, a figura 5 apresenta o framework para integração entre os tipos de conhecimento sendo aplicado para elencar e integrar todos os conhecimentos relacionados ao grid, tanto no uso do software quanto em outros aspectos mais amplos do design.

Como pode ser visto, o grupo da esquerda representa os conhecimentos em design. Nele, os conhecimentos declarativos referentes ao grid envolvem, por exemplo, a sua definição, seus aspectos históricos, tipos existentes, elementos que o compõem, funções e objetivos do seu uso, etc. Já os procedimentais envolvem as habilidades em construir um grid. Isso pode ocorrer através de técnicas manuais, principalmente para a geração e exploração rápida de ideias. Ou através de técnicas de representação digital, utilizando softwares como o Adobe InDesign, para explicitar melhorar as ideias, conseguir um nível maior de precisão e criar representações adequadas para produção. Por fim, os conhecimentos estratégicos envolvem saber escolher quando e como utilizar cada conhecimento anterior, ou seja, quando é melhor utilizar a representação manual e quando é melhor a digital, quando utilizar cada tipo diferente de grid, e quais características adotar em cada caso. 
Figura 5 - Exemplo de aplicação do framework para integrar conhecimentos em software e em design referentes ao elemento grid de design gráfico.

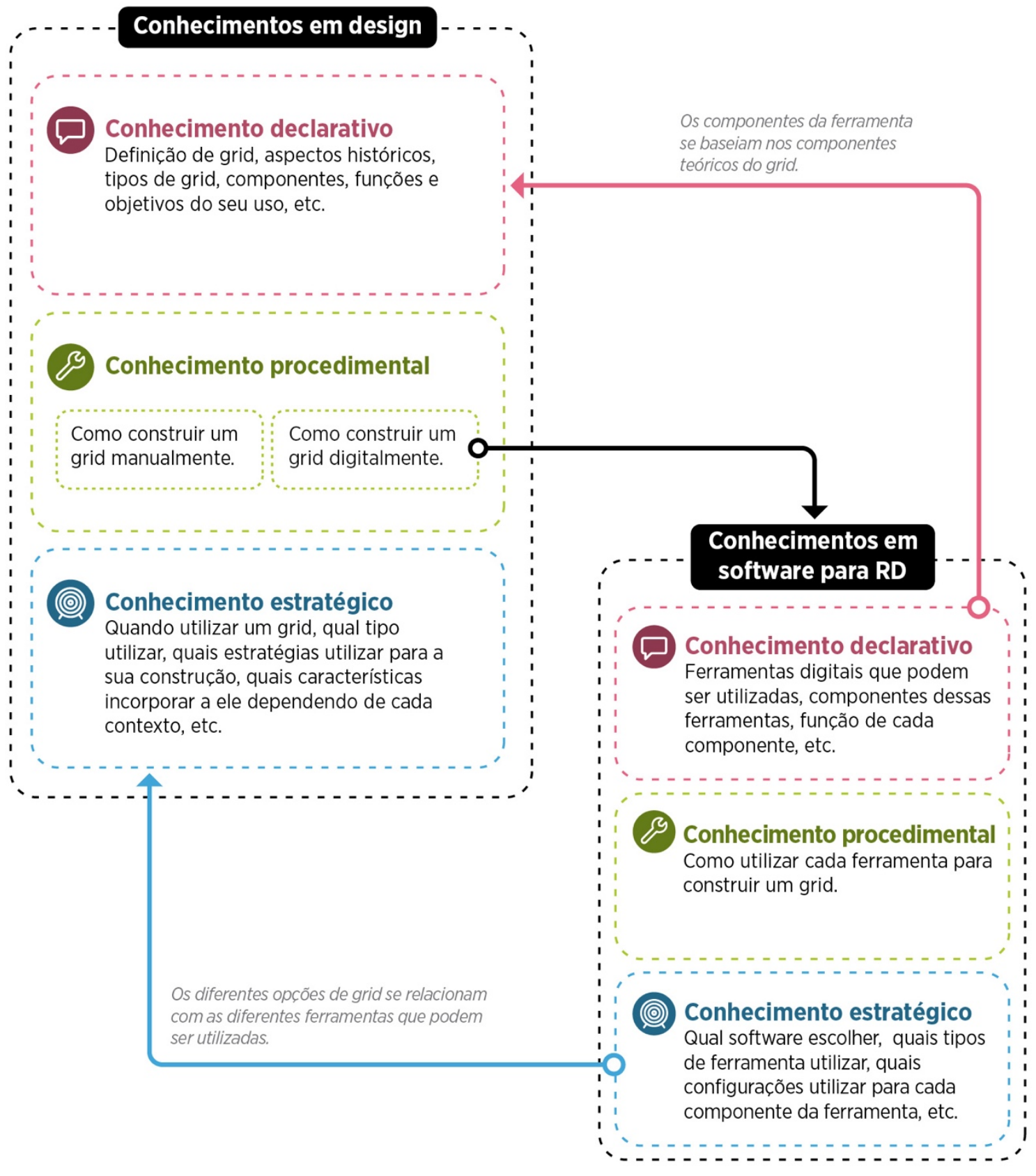

Fonte: 0 autor.

Já o grupo da direita representa os conhecimentos específicos em software. E como pode ser percebido, eles não se encontram separados dos conhecimentos em design, pelo contrário, se conectam a eles como um conhecimento procedimental relacionado a como fazer representações digitais. Porém, também apresentam internamente os três níveis de conhecimentos. Os declarativos envolvem saber quais ferramentas existem para construir um grid e quais são seus elementos e funções. Nesse caso, já encontramos uma nova ligação entre os conhecimentos em software e design. Isso ocorre porque os elementos presentes na configuração do grid no software 
não são arbitrários, mas sim decorrência dos conhecimentos declarativos em design referentes aos componentes do grid, como margem, coluna e guter. Os conhecimentos procedimentais envolvem como operar essas diferentes ferramentas para criar os grids desejados. E, por fim, os conhecimentos estratégicos focam em como escolher qual tipo de ferramenta utilizar e quais configurações adotar para cada uma. Novamente encontramos outra ligação entre os conhecimentos em software e em design. Isso ocorre porque o tipo de ferramenta utilizado vai depender, entre outros fatores, do tipo de grid definido para o projeto, como por exemplo um grid de colunas simétrico, um assimétrico, um modular ou um baseline grid. Cada um deste tipos tem sua implementação facilitada por um tipo diferente de ferramenta do software.

Através do uso do framework é possível, portanto, apresentar os conhecimentos em design e os conhecimentos em software relacionados ao grid de forma completa e integrada. Dessa maneira, é possível ao estudante perceber para que serve esse tipo de elemento, como ele pode ser construído, quando deve ser utilizado e quais tipos e características adotar em cada caso. Assim como permite ao professor organizar os conteúdos a serem abordados durante o processo de ensino.

\section{Conclusões}

Ao término deste artigo acredita-se que o objetivo definido foi atingido, já que um framework conceitual para a integração de conhecimentos durante o ensino de softwares para representação de design foi desenvolvido e proposto. A base para o seu desenvolvimento foi a teoria dos tipos de conhecimento, que defende a existência de três categorias de conhecimento: declarativo, procedimental e estratégico. E seu uso pretende auxiliar a solução de dois problemas durante o ensino de softwares para representação: (a) a falta de integração dos conhecimentos estratégicos em software com os demais e (b) a falta de integração entre conhecimentos em software e conhecimentos em design.

Para resolver esses problemas, o framework primeiro evidência a existência dos conhecimentos estratégicos e o seu papel durante a seleção e utilização dos demais conhecimentos. Além disso, o framework também permite perceber a relação entre conhecimentos em software e em design, sendo que o primeiro pode ser encapsulado como um conhecimento procedimental de design, permitindo assim a sua integração com ele.

Como próximos passos para pesquisas futuras, o framework precisa ser testado em situações reais de ensino, de forma a validar sua eficácia e eficiência em auxiliar na resolução dos problemas identificados.

\section{Referências}

ARNOLD, J. Putting CAD In Its Place : A New Approach For Enhanced Virtual Product Design Teaching. IDSA 2010 White Paper, 2010.

CHESTER, I. Teaching for CAD expertise. International Journal of Technology and Design Education, v.17, n.1, 2007, p.23-35.

GALLE, P. Design as intentional action: a conceptual analysis. Design Studies, v.20, n.1, 1999, p. 
$57-81$.

KUANG, Y. Problems and solutions on the teaching of computer-aided industrial design. 9th International Conference on Computer-Aided Industrial Design and Conceptual Design, 2008.

MARSHALL, L. \& MEACHEM, L. Direct or directed: orchestrating a more harmonious approach to teaching technology within an Art \& Design Higher Education curriculum with special reference to visual communications courses. Learning, Media and Technology, v. 32, n.1, 2007, p. 41-52.

PINTO, A. C. Aprender a aprender o quê? Conteúdos e estratégias. Psicologia, Educação e Cultura, v. 2, n.1, 1996, p. 37-53.

SPITZ, R. Dirty hands on the keyboard. Sixth International Symposium on Eletronic Art - ISEA'95, Montreal, 1995.

ZHANG, F.; YANG, C. \& ZHU, Y. A Study of CAID Teaching. 9th International Conference on Computer-Aided Industrial Design and Conceptual Design, 2008.

ZHU, Y. \& ZHANG, Z. Reseach on CAID Teaching Based on Design Process. 2010 IEEE 11th International Conference on Computer- Aided Industrial Design \& Conceptual Design (CAIDCD), 2010. 